\title{
Antibiofilm surface functionalization of catheters by magnesium fluoride nanoparticles
}

This article was published in the following Dove Press journal:

International Journal of Nanomedicine

29 February 2012

Number of times this article has been viewed

\section{Jonathan Lellouche ${ }^{1,2}$ \\ Alexandra Friedman ${ }^{2}$ \\ Roxanne Lahmi' \\ Aharon Gedanken ${ }^{2}$ \\ Ehud Banin'}

'The Mina and Everard Goodman Faculty of Life Sciences, ${ }^{2}$ The Kanbar Laboratory for Nanomaterials, Department of Chemistry, The Bar-Ilan Institute of Nanotechnology and Advanced Materials, Bar-llan University, Ramat-Gan, Israel
Correspondence: Ehud Banin

The Mina and Everard Goodman Faculty of Life Sciences, The Bar-llan Institute of Nanotechnology and Advanced Materials, Bar-Ilan University, Ramat-Gan, 52900, Israel

$\mathrm{Tel}+\mid 97235317288$

Fax +I 97235384058

Email ehud.banin@biu.ac.il
Abstract: The ability of bacteria to colonize catheters is a major cause of infection. In the current study, catheters were surface-modified with $\mathrm{MgF}_{2}$ nanoparticles (NPs) using a sonochemical synthesis protocol described previously. The one-step synthesis and coating procedure yielded a homogenous $\mathrm{MgF}_{2} \mathrm{NP}$ layer on both the inside and outside of the catheter, as analyzed by high resolution scanning electron microscopy and energy dispersive spectroscopy. The coating thickness varied from approximately $750 \mathrm{~nm}$ to $1000 \mathrm{~nm}$ on the inner walls and from approximately $450 \mathrm{~nm}$ to approximately $580 \mathrm{~nm}$ for the outer wall. The coating consisted of spherical $\mathrm{MgF}_{2}$ $\mathrm{NPs}$ with an average diameter of approximately $25 \mathrm{~nm}$. These $\mathrm{MgF}_{2} \mathrm{NP}$-modified catheters were investigated for their ability to restrict bacterial biofilm formation. Two bacterial strains most commonly associated with catheter infections, Escherichia coli and Staphylococcus aureus, were cultured in tryptic soy broth, artificial urine and human plasma on the modified catheters. The $\mathrm{MgF}_{2}$ NP-coated catheters were able to significantly reduce bacterial colonization for a period of 1 week compared to the uncoated control. Finally, the potential cytotoxicity of $\mathrm{MgF}_{2} \mathrm{NPs}$ was also evaluated using human and mammalian cell lines and no significant reduction in the mitochondrial metabolism was observed. Taken together, our results indicate that the surface modification of catheters with $\mathrm{MgF}_{2} \mathrm{NPs}$ can be effective in preventing bacterial colonization and can provide catheters with long-lasting self-sterilizing properties.

Keywords: $\mathrm{MgF}_{2} \mathrm{NP}$ coating, modified surfaces, bacterial colonization, human plasma, artificial urine, biocompatibility

\section{Introduction}

Biomedical devices and implants are commonly used in the health care system. Over the past three decades, the number of artificial hip and knee implants has increased markedly, and stents, heart valves, vascular grafts, catheters, and other implanted devices have been used widely to save lives and to restore the quality of life to millions of people worldwide. Unfortunately, these abiotic surfaces are prone to bacterial colonization and device-related infections caused by bacterial attachment and proliferation. ${ }^{1-5}$

More than 200,000 nosocomial bloodstream infections occur each year in the USA and most of them are related to the use of intravascular devices. ${ }^{6,7}$ Central venous catheters are particularly prone to colonization. ${ }^{8,9}$ According to recent estimates, $5 \%$ of the 7 million central venous catheters inserted annually are associated with catheter-related bloodstream infections. ${ }^{710}$ Chronic indwelling urinary catheters also increase the risk of infection, accounting for approximately $80 \%$ of all nosocomial urinary tract infections. ${ }^{11,12}$ In an attempt to minimize the risk of infection associated with short-term biomedical devices, prophylactic measures are applied. 
In addition, catheters are replaced at frequent intervals but such preventive replacement schedules impose considerable inconvenience to the patient and increase operation costs for the health care system. ${ }^{13}$

The current situation raises the urgent need to design surfaces that can restrict bacterial colonization and biofilm formation. One promising approach is to provide the surface with antimicrobial properties. ${ }^{14-17}$ A number of such devices have been developed ${ }^{18-21}$ and tested with variable success in clinical studies..$^{9,10,12}$ However, the ideal catheter, a catheter that combines low-cost coating technology, a wide spectrum, and long-lasting antimicrobial properties, as well as safe utilization, has yet to be developed.

In this context, nanotechnology-driven approaches are expected to provide new opportunities for preventing and fighting biofilm-mediated infections via the extended use of atomic scale-tailored nanomaterials. The most interesting and recent example uses silver-based compounds. The surface functionalization by silver nanoparticles (NPs) of polyurethane and plastic catheters was shown to have antibacterial/antibiofilm activity against a broad range of pathogenic strains (eg, Escherichia coli, Enterococci, Pseudomonas aeruginosa, and coagulase-negative Staphylococci). ${ }^{18,19,22}$ However, since silver may also have cytotoxic effects, there is growing concern regarding the long-term exposure and use of silver-based nanomaterials. ${ }^{23-26}$ Thus, alternative nanomaterial compounds that can inhibit the bacterial colonization of catheter surfaces must be developed.

Our group has recently demonstrated the antibacterial and antibiofilm properties of highly crystalline, $25 \mathrm{~nm}$-sized magnesium fluoride $\left(\mathrm{MgF}_{2}\right)$ NPs using either a microwave or sonochemical chemistry for their synthesis. ${ }^{27,28}$ Antimicrobial activity of $\mathrm{MgF}_{2}$ NPs was highly dependent on the size of the NP. ${ }^{28}$ Our results revealed that the NPs penetrate the cells, reduce the internal $\mathrm{pH}$, cause disruption to the membrane potential, and enhance lipid peroxidation..$^{27,28} \mathrm{We}$ also utilized this new metal-fluoride nanomaterial to coat glass slide coupons and showed that the coated surfaces can restrict bacterial colonization and biofilm formation for up to 7 days. ${ }^{28}$ Results thus far suggest that the most active antibacterial nanomaterials exhibit an increased chemical surface-mediated reactivity, mainly due to their large surface-to-volume ratios and defined crystallographic structures.

The objective of the current study was to present a sonochemical method for depositing $\mathrm{MgF}_{2}$ NPs on latex-based catheters in a one-step process, and to obtain a long-lasting $\mathrm{MgF}_{2} \mathrm{NP}$ coating on both sides of the catheter (namely, internal and external), even following exposure to various biological fluids (such as plasma and urine). The biocompatibility of $\mathrm{MgF}_{2} \mathrm{NP}$-coated catheters was also examined and preliminary results suggest that human cell lines are tolerant in contact with the $\mathrm{MgF}_{2} \mathrm{NP}$-coated latex. These findings provide a new approach for the future development of self-sterilizing catheter coatings based on magnesium fluoride NPs.

\section{Materials and methods Catheter-coating procedure and characterization}

Latex-based Foley catheter (Unomedical, Birkerød, Denmark) $5 \mathrm{~cm}$ length segments were coated by placing the catheter segments directly into the sonochemical reaction medium according to the methodology described previously. ${ }^{28}$ In brief, magnesium (II) acetate tetrahydrate $\left(\left[\mathrm{Mg}(\mathrm{Ac})_{2} \cdot\left(\mathrm{H}_{2} \mathrm{O}\right)_{4}\right], 99 \%\right.$ purity; Sigma-Aldrich, St Louis, MO) and concentrated hydrofluoric acid (HF, 32\% weight aqueous solution, ACS grade, BioLab, Albany, Auckland) were dissolved in double-distilled water (DDW; $100 \mathrm{~mL}$ ) at a 1:2 equivalent ratio. The mixture (0.01 M HF) was irradiated with a high-intensity ultrasonic horn (Ti-horn [Sonics and Materials, Newton, CT], $20 \mathrm{kHz}$, $750 \mathrm{~W} \times \mathrm{cm}^{-2}, 60 \%$ power modulation) under argon (60 minutes, room temperature). The products were washed thoroughly with DDW $(3 \times 10 \mathrm{~mL})$, absolute EtOH $(2 \times 10 \mathrm{~mL})$, and dried in vacuum $\left(10^{-2} \mathrm{~mm} \mathrm{Hg}\right)$ in an inert glove box $\left(\mathrm{O}_{2}<1 \mathrm{ppm}\right)$. It should be emphasized that since catheters are soaked in the reaction medium the coating procedure simultaneously coats the external and internal sides of the catheter.

To verify the NP crystallinity, powder X-ray diffraction (XRD) measurements were carried out on a Bruker (Madison, WI) D8 diffractometer using $\mathrm{Cu} \mathrm{K} \alpha$ radiation $(\lambda=1.5418 \AA)$. Peak fitting and lattice parameter refinement were computed using the EVA software program (v 5.0; Bruker Analytical $\mathrm{X}$-ray Systems). The NP morphology was characterized using a high-resolution scanning electron microscope (HR SEM; JEOL-6700F [JEOL, Tokyo, Japan], accelerating voltage $15 \mathrm{kV}$ ) and a high-resolution transmission electron microscope (HR TEM; JEOL-2010 HR TEM, accelerating voltage $200 \mathrm{kV}$ ). NP samples for HR SEM analysis were chromium coated before imaging. NP samples for HR TEM analysis were prepared in absolute EtOH (ultrasonic dispersion), deposited onto a copper-coated grid (drop deposition), and then dried under vacuum $\left(10^{-2} \mathrm{mmHg}\right)$ before sample processing. The theoretical size and the size distribution of the NPs were calculated by the Debye-Scherrer equation and determined from the measurement $(n=200)$ of images taken with HR SEM, respectively. After completion of sonication, the sonochemically coated catheters were washed 
with DDW $(3 \times 10 \mathrm{~mL})$ followed by absolute $\mathrm{EtOH}(2 \times 10 \mathrm{~mL})$ and allowed to dry in vacuum $\left(10^{-2} \mathrm{mmHg}\right)$. Next, the samples were coated with chromium and imaged by HR SEM (JEOL$6700 \mathrm{~F}$, accelerating voltage $15 \mathrm{kV}$ ).

To determine the amount of $\mathrm{MgF}_{2}$ NPs on the catheter surfaces, the outer circumference of the tubing (a layer of $0.1 \mathrm{~cm}$ ) was removed using a sharp scalpel. The removed layer was soaked in $5 \mathrm{M}$ of $\mathrm{HNO}_{3}$ and the magnesium concentration was then determined by inductively coupled plasma (ICP; ULTIMA 2, Horiba Scientific, Edison, NJ). The dissolution in nitric acid $\left(\mathrm{HNO}_{3}, \mathrm{ACS}\right.$ grade, BioLab) was repeated for the tubing remaining after the removal of the outer surface. This approach allowed us to measure the relative coating on the inner and outer surfaces. Uncoated catheter segments served as a negative control. To evaluate the coating distribution on the surface, we mapped the magnesium and fluorine elemental distributions on the inner and outer walls by energy dispersive X-ray analysis (EDS;EDAX, Mahwah, NJ) apparatus on SEM (FEI, Inspect ${ }^{\mathrm{TM}}$ $\mathrm{S}$, Hillsboro, OR). Elemental mapping was performed at both $15 \mathrm{keV}$ and $0.58 \mathrm{nA}$ with a resolution of $133 \mathrm{eV}$. Maps were created in most cases from 100 scan frames using a dwell time of $100 \mu$ s and $512 \times 384 \mathrm{pixel} /$ frame resolution.

\section{Bacterial cultures and growth conditions}

For static biofilm assays, Escherichia coli C600 (E. coli) and Staphylococcus aureus FRF119 (S. aureus) were grown in tryptic soy broth (TSB; Difco ${ }^{\mathrm{TM}}, \mathrm{BD}$, Franklin Lakes, NJ) or tryptic soy broth $66 \%$ supplemented with $0.2 \%$ glucose $(\mathrm{TSB}-\mathrm{Glu})^{28}$ For the continuous culture flow model, E. coli and $S$. aureus were grown in TSB $(\mathrm{pH}=7.6)$ or TSB-Glu $(\mathrm{pH}=7.8,10 \%)$ diluted in DDW $(90 \%)$, respectively. ${ }^{29-31}$ We also utilized human plasma (Magen David Adom Blood Bank, Shiba Hospital, Tel-Hashomer, Israel) for growth. In this case, fresh citrated $(0.37 \%$ citrate $)$ human plasma (67\%) was diluted in TSB or TSB-Glu (33\%) for E. coli and S. aureus growth, respectively. The plasma was diluted to $67 \%$ with TSB or TSB-Glu to enhance bacterial growth $(\mathrm{pH}=7.4) .{ }^{32}$ Finally, we also grew bacteria in artificial urine that was reconstructed using human urine proteins (Sigma-Aldrich) and salts, according to the manufacturer's instructions. The $\mathrm{pH}$ of the reconstituted urine was adjusted to $\mathrm{pH}=7.5$. All experiments were incubated in aerobic conditions at $37^{\circ} \mathrm{C}$.

\section{$\mathrm{MgF}_{2}$ NP-coating stability}

To determine the time-dependent stability of the $\mathrm{MgF}_{2} \mathrm{NP}$ coating, the inner wall was tested using a continuous-flow model using the same bacterial media and growth conditions described above. Briefly, TSB, TSB-Glu, urine, or plasma was allowed to flow through the catheter at a rate of $10 \mathrm{~mL}$ per hour and aliquots from the flow-through were taken for analysis (see Antibiofilm assays). To examine the stability of the external coating, the catheter was incubated in the medium under static conditions (without any flow) and aliquots were taken at various time points for analysis.

Stability was characterized by determining the amount of NPs and/or $\mathrm{Mg}^{+2}$ released from the catheter surface. The samples taken were centrifuged for 30 minutes at 16,000 relative centrifugal force (centrifuge 5418, Eppendorf, Harburg, Germany). The supernatant was analyzed by inductively coupled plasma ICP to determine the $\mathrm{Mg}^{+2}$ concentrations. To detect the potential presence of NPs, we removed the supernatant, washed it with DDW $(3 \times 10 \mathrm{~mL})$, and treated it for 60 minutes with a solution of $10 \%(\mathrm{v} / \mathrm{v})$ sodium dodecyl sulfate (Sigma-Aldrich) and 2\%(v/v) $\beta$-mercaptoethanol in water to denature the potential proteins present on the NP surface. The proteins were removed from the solution using $\mathrm{NaCl}(3 \mathrm{M})$ solution and re-suspended in ethanol (ACS grade, BioLab) for dynamic light scattering (DLS; N-4 particle size analyzer, Beckman Coulter Inc, Brea, CA), NP-measurements, and TEM imaging.

\section{Antibiofilm assays}

We evaluated the antibiofilm properties of the two sides of the coated catheter (the external and internal walls).

The external wall was assayed using a static biofilm assay. The $5 \mathrm{~cm}$ catheter segments were placed in a six-well plate (Greiner Bio One, Frickenhausen, Germany). Each well contained a $5 \mathrm{~mL}$ bacterial suspension of either $E$. coli or $S$. aureus at a final concentration of approximately $3 \times 10^{8}$ colony forming units $(\mathrm{CFU}) / \mathrm{mL}$ solution in the appropriate growth media. After 1, 3, and 7 days of incubation, the undesired $S$. aureus and E. coli biofilm cells grown in the inside wall were fixed with glutaraldehyde and paraformaldehyde for 1 hour. The outside wall biofilm cells were detached by exposure to low energy sonication water bath (TRANSSONIC 460, Elma, Singen, Germany) for 1 minute and centrifuged at $2150 \mathrm{~g}$ for 5 minutes to form a pellet of cells. A viable count was determined by resuspending the cells in media and plating serial dilutions on Luria Bertani (Difco).

The inside wall was assayed by a continuous culture flow model. A $5 \mathrm{~cm}$ catheter segment was inoculated with approximately $3 \times 10^{8} \mathrm{CFU} / \mathrm{mL}$ of an E. coli and $S$. aureus culture. The flow (in the indicated media) was initiated after 1 hour with a flow rate of $10 \mathrm{~mL}$ per hour. The system was incubated at $37^{\circ} \mathrm{C}$ for 7 days and the biofilm was extracted from the catheter as described previously. ${ }^{33,34}$ 
The cells were diluted in 1\% Luria-Bertani and plated for viable counting. The relative reduction in colonization, $\mathrm{N} / \mathrm{N}_{0}$, was determined by calculating the CFU per $\mathrm{mL}$ of the culture. The terms $\mathrm{N}_{0}$ and $\mathrm{N}$ stand for the numbers of $\mathrm{CFU}$ present on uncoated and $\mathrm{MgF}_{2} \mathrm{NP}$-coated catheters, respectively. An alternative approach to determine the biofilm biomass crystal violet (CV) staining was also utilized. Briefly, catheter segments (the external and internal walls) were washed twice with DDW to remove non attached cells and stained with 1\% CV (Sigma-Aldrich) for 15 minutes at room temperature. Stained wells were then washed five times with DDW and the remaining CV was eluted by the addition of absolute ethanol for 15 minutes. The biofilm biomass was then determined by measuring the absorbance at $\mathrm{OD}_{595}$. Data were analyzed by analysis of variance and results were considered to be significant at $P<0.05$.

\section{Cell culture and cytotoxicity assay}

HeLa, human embryonic kidney 293 (HEK 293), and mouse embryonic fibroblasts (MEFs) cell lines were cultured in petri dishes in Dulbecco's Minimum Essential Medium (Gibco ${ }^{\circledR}$ DMEM, Life Technologies Corp, Grand Island, NY) supplemented with 10\% fetal calf serum, 1\% penicillin/streptomycin, and 1\% glutamine. The cells were seeded at a density of 10,000 cells per well in 24-well tissue culture plates (Greiner), which contained $\mathrm{MgF}_{2}$-coated and uncoated latex-based catheter segments. The cells were incubated at $37^{\circ} \mathrm{C}$ in a humidified atmosphere of $5 \% \mathrm{CO}_{2}$ for 24 hours. Following incubation, the catheter segments (with attached cells) were removed for further analysis, as described below.

For microscopy imaging, the HeLa cells that were grown on the catheters were fixed in $4 \%$ paraformaldehyde for 30 minutes, washed in phosphate-buffered saline, and then blocked with $20 \%$ fetal bovine serum/0.5\% Triton X-100 (Sigma-Aldrich) in phosphate-buffered saline for 1 hour and incubated overnight with a primary antibody ( $\beta$-tubulin monoclonal antibody; Developmental Studies Hybridoma Bank, Iowa City, IA) at $4^{\circ} \mathrm{C}$. After washing, the catheters were incubated with a rhodamine-conjugated anti-mouse secondary antibody at 1:150 dilution (Jackson Immuno Research Laboratories Inc, West Grove, PA). The DNA was visualized with 4',6-diamidino-2-phenylindole stain (SigmaAldrich) and the catheters were mounted on slides with the VECTASHIELD ${ }^{\circledR}$ mounting solution (Vector Laboratories Inc, Burlingame, CA) and sealed. Imaging was obtained from an ApoTome microscope (Axio Imager, Carl Zeiss MicroImaging GmbH, Jena, Germany).
The cells were also analyzed for cell viability using a colorimetric 3-(4,5-dimethylthiazol-2-yl)-2,5-diphenyltetrazolium bromide (MTT) assay, as described by Mosmann. ${ }^{35}$ The assay is based on the ability of metabolically active cells to reduce MTT, a yellow tetrazolium salt, to a purple formazan. In brief, following 24 hours of incubation, $100 \mu \mathrm{L}$ of a MTT $(5 \mathrm{mg} / \mathrm{mL})$ labeling mixture was added to each well and the microplate was incubated for 15-45 minutes. After incubation, the MTT-containing medium was removed from the microplate and the insoluble formazan dissolved in $50 \mu \mathrm{L}$ of dimethyl sulfoxide. Cell viability was determined by measuring the absorbance at $\mathrm{OD}_{570}$ using a microplate reader $\left(\right.$ Synergy ${ }^{\text {TM }} 2$, BioTek Instruments Inc, Winooski, VT).

\section{Results and discussion $\mathrm{MgF}_{2} \mathrm{NP}$ catheter-coating procedure and characterization}

Sonochemistry has been shown to effectively coat various flat surfaces, including rigid and soft polymers. ${ }^{17,36,37}$ However, this one-step synthesis and coating procedure was never applied for coating more structurally complex surfaces such as tubes in which both the internal and external sides need to be coated. However, as the synthesis and coating procedure is obtained in the same reaction chamber, we reasoned that as the solution will penetrate the inside of the catheter, this will also simultaneously allow the coating of the internal part. As described in the experimental procedure, catheters were coated by adding segments directly into the chemical reaction medium, using the same reaction parameters described for the synthesis of the NPs (see Figure S1). In the sonochemical synthesis, stable $\mathrm{MgF}_{2} \mathrm{NP}$ coatings are formed by the high energy created by the collapse of the cavitation bubbles. ${ }^{38}$ This collapse creates very high temperatures and pressure, conditions leading to the rupture of chemical bonds (Figure 1). ${ }^{38,39}$ According to the interpretation suggested for the sonochemical coating process, microjets are formed after the collapse of the acoustic bubble near a solid surface (Figure 1). These microjets throw the newly formed NPs at the solid substrate at such a high speed $(>200 \mathrm{~m} / \mathrm{second})$ that the NPs could penetrate surfaces to a depth of up to $90 \mathrm{~nm} \cdot{ }^{28,38,40}$

Our initial characterization measurements were aimed at determining the shape and the size of the $\mathrm{MgF}_{2} \mathrm{NPs}$ formed in the sonochemical reaction. The $\mathrm{MgF}_{2} \mathrm{NP}$-coated catheters were imaged by HR SEM (Figure 2). The catheter surfaces were completely covered, with spherical NPs having an average size of approximately $25 \mathrm{~nm}$ (Figure 2). The size 


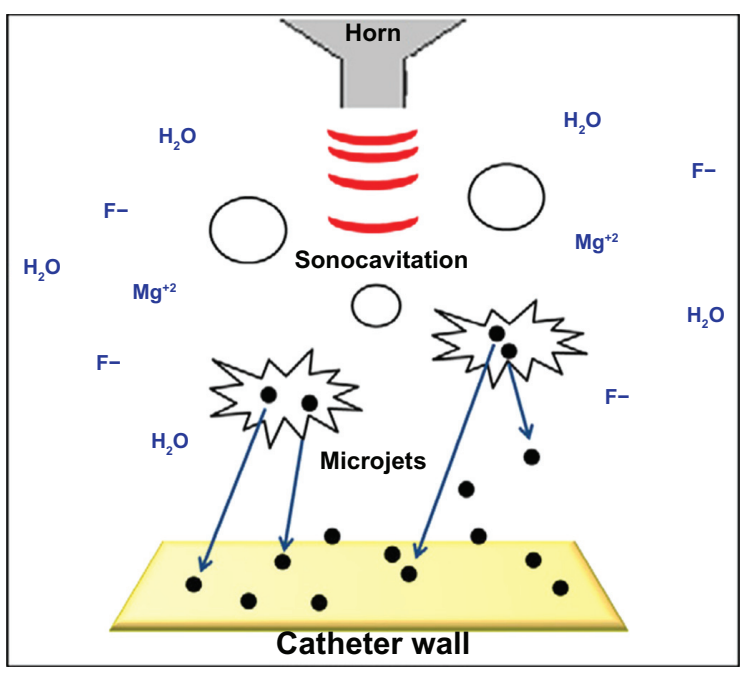

Figure I General view of the $\mathrm{MgF}_{2}$ NPs synthesis and NPs deposition on catheter walls by sonochemistry. $\mathrm{MgF}_{2}$ (black spheres) formation under ultrasonic irradiation (red waves). Microjets (blue arrows) were formed after the collapse of the acoustic bubble near the catheter wall and throw the NPs to create $\mathrm{MgF}_{2} \mathrm{NP}$-coating. Abbreviation: NPs, nanoparticles.

and the morphology are similar to the data measured by HR TEM and XRD for the suspended NPs (formed under similar reaction conditions, but without the catheters in the reaction vessel: see Figure S1).

The side view of the $\mathrm{MgF}_{2} \mathrm{NP}$-coated catheter revealed coatings on both the external and internal walls of the catheter. The coating thickness varied from approximately 750 to approximately $1000 \mathrm{~nm}$ on the inner walls and from approximately 450 to approximately $580 \mathrm{~nm}$ for the outer wall (Figure 2). The quantification of the $\mathrm{MgF}_{2} \mathrm{NPs}$ deposited

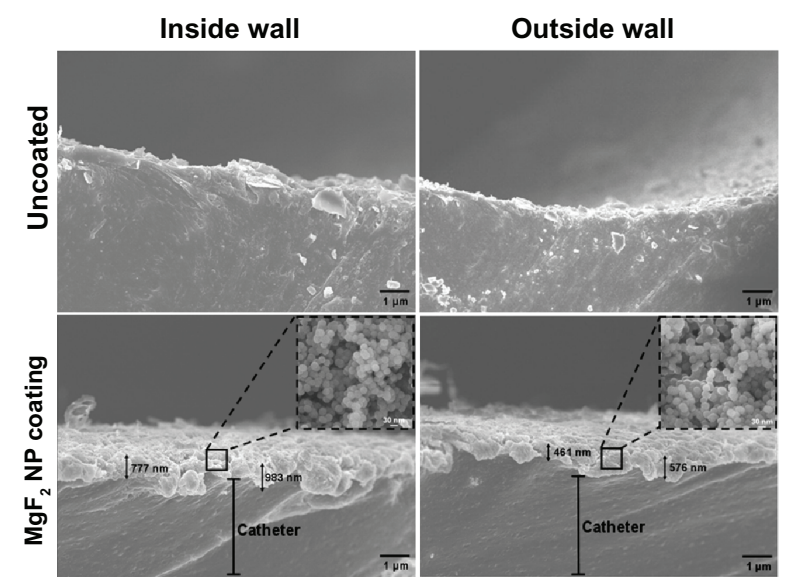

Figure 2 Imaging of sonochemical $\mathrm{MgF}_{2} \mathrm{NP}$ catheter coating. Catheters were coated using a sonochemical procedure described in the experimental section. HR SEM images of the lateral sections of the internal and external walls of uncoated and $\mathrm{MgF}_{2}$ NP-coated catheters are presented. Inserts provide an enlarged view of the coating showing the typical spherical $\mathrm{MgF}_{2} \mathrm{NP}$ structure.

Note: Black arrows indicate the thickness of the $\mathrm{MgF}_{2} \mathrm{NP}$ coating.

Abbreviations: HR SEM, high resolution scanning electron microscope; NP, nanoparticle. during the synthesis confirms this fact, and the amount of NPs deposited varies from $0.021( \pm 0.003)$ to $0.010( \pm 0.005)$ $\mathrm{mg} / \mathrm{cm}^{2}$ for the inside and outside walls, respectively. We also evaluated the homogeneity of the coating deposition by elemental mapping analysis of magnesium and fluorine using EDS. Figure 3 shows the distribution of the $\mathrm{MgF}_{2} \mathrm{NP}$ coating on the two walls. $\mathrm{MgF}_{2} \mathrm{NP}$-coated catheters present a large and homogeneous distribution of the signals emitted from magnesium and fluorine detection. We have also scanned the uncoated catheter for $\mathrm{Mg}$ and $\mathrm{F}$, and while a very low magnesium signal was detected, fluorine could not be found on the uncoated segments. This can most likely be explained by the fact that the magnesium we detected comes from traces of surfactants or residues in the water used during the catheter fabrication processing. ${ }^{41}$

As described above, we did observe a difference in the coating between the external and internal surfaces. Relating to the weight quantification of the $\mathrm{MgF}_{2} \mathrm{NP}$ coating and the HR SEM imaging, we also detected a higher fluorescence emission signal of magnesium and fluorine from the inner

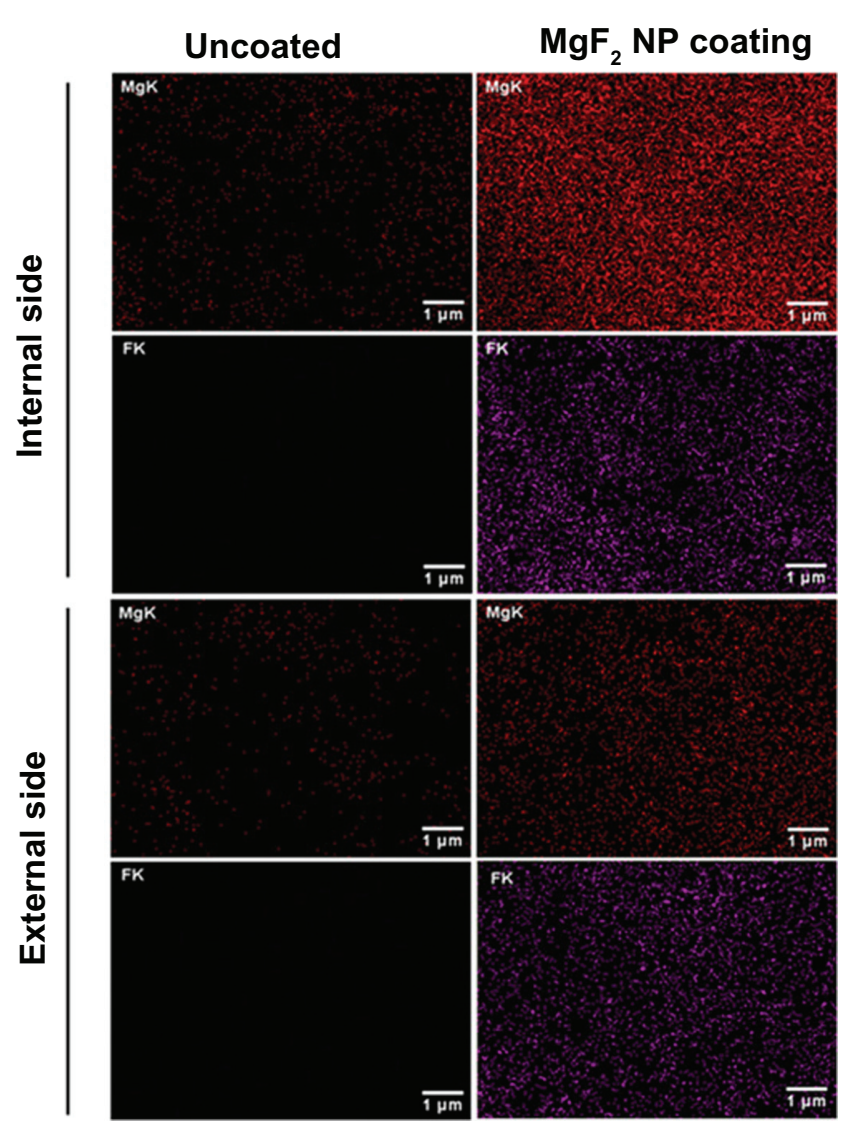

Figure 3 Distribution of the $\mathrm{MgF}_{2} \mathrm{NP}$ coating on the catheter's surface. Elemental mapping analysis of magnesium (red) and fluor (purple). The signals were detected from the internal and external sides of coated and uncoated catheters with $\mathrm{MgF}_{2} \mathrm{NPs}$.

Abbreviation: NP, nanoparticle. 
wall compared to that obtained from the external wall (Figure 3). One of the possible explanations for this phenomenon could be in the surface topography. The creation of acoustic bubbles is supported by the roughness of the surface. ${ }^{38}$ A rougher internal surface of the catheter helps in the separation of the water molecules, thus forming the acoustic cavity. Furthermore, as more bubbles are created and collapse inside the catheter, an increase in the deposition of $\mathrm{MgF}_{2} \mathrm{NPs}$ on the internal wall is expected.

\section{Stability of the $\mathrm{MgF}_{2} \mathrm{NP}$ coating}

To examine the stability of the coating, we began by exposing the $\mathrm{MgF}_{2} \mathrm{NP}$-coated catheters to growth media (without bacteria). The coating stability of both the external and internal sides were examined under static and flow conditions. To exclude the possibility of NPs leaching from the catheter surfaces, we conducted DLS measurements and TEM imaging of the biological medium following contact with the inside and outside catheter walls at regular time points during the experiment. No $\mathrm{MgF}_{2} \mathrm{NP}$ leaching was detected from the native surface during the entire 7 days (data not shown). This observation is reinforced by HR SEM imaging (Figure 4) that revealed stable $\mathrm{MgF}_{2} \mathrm{NP}$ coating on the inside and outside walls, even following the 7-day exposure. The coated catheter surface remained intact and the $\mathrm{MgF}_{2} \mathrm{NP}$ coating was still homogenous (Figure 4). It should be emphasized that an organic coating, probably composed mainly of proteins, was observed on the catheter walls exposed to urine and plasma, due to the attachment of proteins present in high concentrations in urine and plasma (Figure 4). Taken together, these results confirm that the sonochemical technique can provide a stable $\mathrm{MgF}_{2} \mathrm{NP}$ coating on latex catheter surfaces.

The release of $\mathrm{Mg}^{+2}$ ions from the coatings was also measured by ICP analysis. Figure 5 depicts the concentration measurements of $\mathrm{Mg}^{+2}$ released from the external (Figure 5A) and internal (Figure 5B) sides during exposure to TSB/ TSB-Glu, artificial urine, and plasma. The amounts of $\mathrm{Mg}^{+2}$ detected were at the $\mathrm{nM}$ levels (Figure 5). Furthermore, the levels of $\mathrm{Mg}^{+2}$ reached a steady state after approximately 24 hours and remained constant for the next 7 days in all the tested media.

It is interesting to note that we observed a difference in the amounts of $\mathrm{Mg}^{+2}$ released from the external (Figure 5A) and internal walls (Figure 5B). The $\mathrm{Mg}^{+2}$ concentrations released from the external wall were two-fold higher than those found in the internal wall. The lower $\mathrm{Mg}^{+2}$ concentration measured from coating exposed to plasma and TSB varied from approximately $4.74 \mathrm{nM}$ (plasma) to $7.46 \mathrm{nM}$ (TSB) and from $8.40 \mathrm{nM}$ (plasma) to $14.27 \mathrm{nM}$ (TSB) for the internal and external walls, respectively (Figure 5A and B). The concentration of $\mathrm{Mg}^{+2}$ released from catheters exposed to urine varied from $7.30 \mathrm{nM}$ to $9.63 \mathrm{nM}$ for the internal and external walls, respectively. One possible explanation for these differences can be attributed to the difference in the continuous flow and static models tested and their influence on the steady-state dissolution of $\mathrm{MgF}_{2}$ NPs. Future work will be required to understand the exact phenomenon. In addition, we observed a difference in the release of $\mathrm{Mg}^{+2}$ when $\mathrm{MgF}_{2} \mathrm{NP}$ coatings were exposed to different biological fluids. When exposed to urine and plasma, both walls displayed significantly less $\mathrm{MgF}_{2}$ dissolution compared to TSB and TSB-Glu. This decrease may be attributed to the attachment of proteins present in high concentrations in urine and plasma, which provide a "protective barrier" against the mechanical frictions between the medium and the catheter, and prevent the detachment of the external layer of the coating. It should be emphasized that this conditioning film may also affect the antimicrobial activity of the coating (see Antibiofilm properties of $\mathrm{MgF} 2 \mathrm{NP}$-coated catheters).

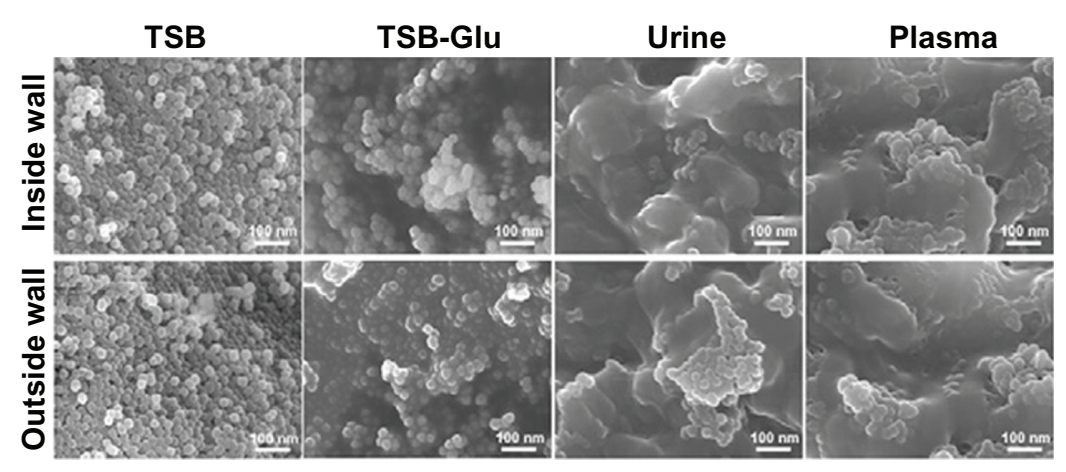

Figure 4 Catheter surface topography after incubation with biological fluids. HR SEM images of the inside and outside walls of $\mathrm{MgF}_{2} \mathrm{NP}$-coated catheters after 7 days exposure in TSB, TSB-Glu, urine, and plasma, as described in the experimental section.

Abbreviations: Glu, glucose; HR SEM, high resolution scanning electron microscope; NP, nanoparticle; TSB, tryptic soy broth. 
A

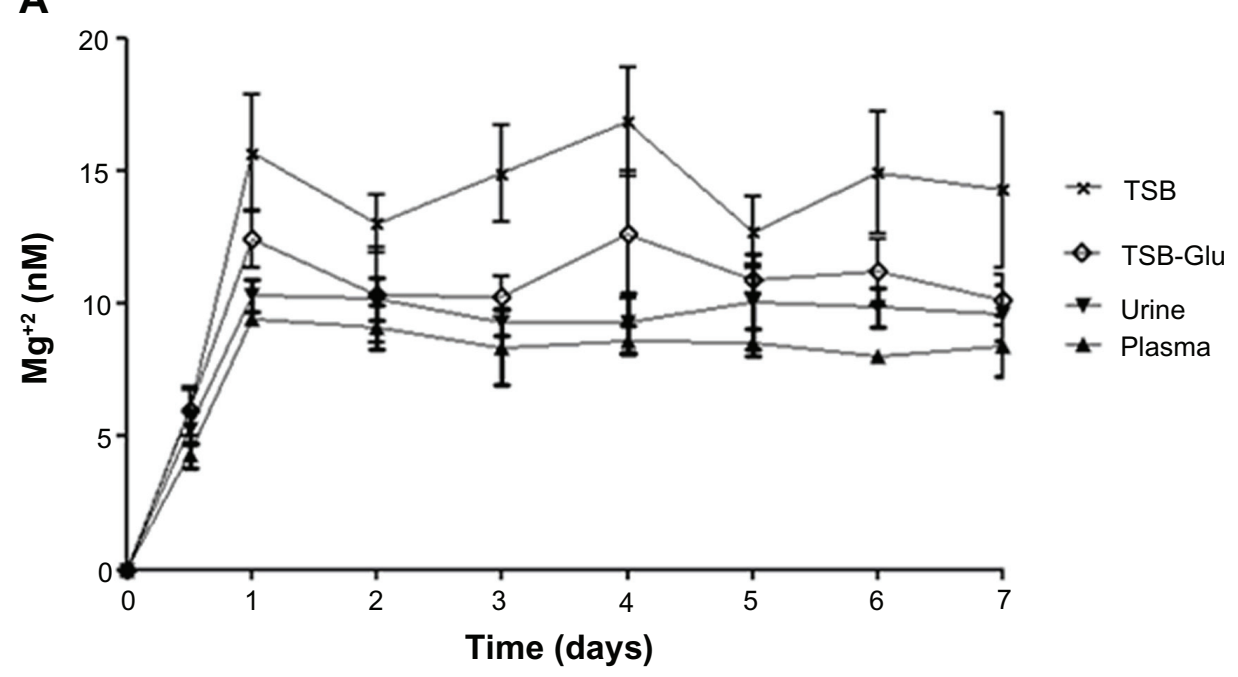

B

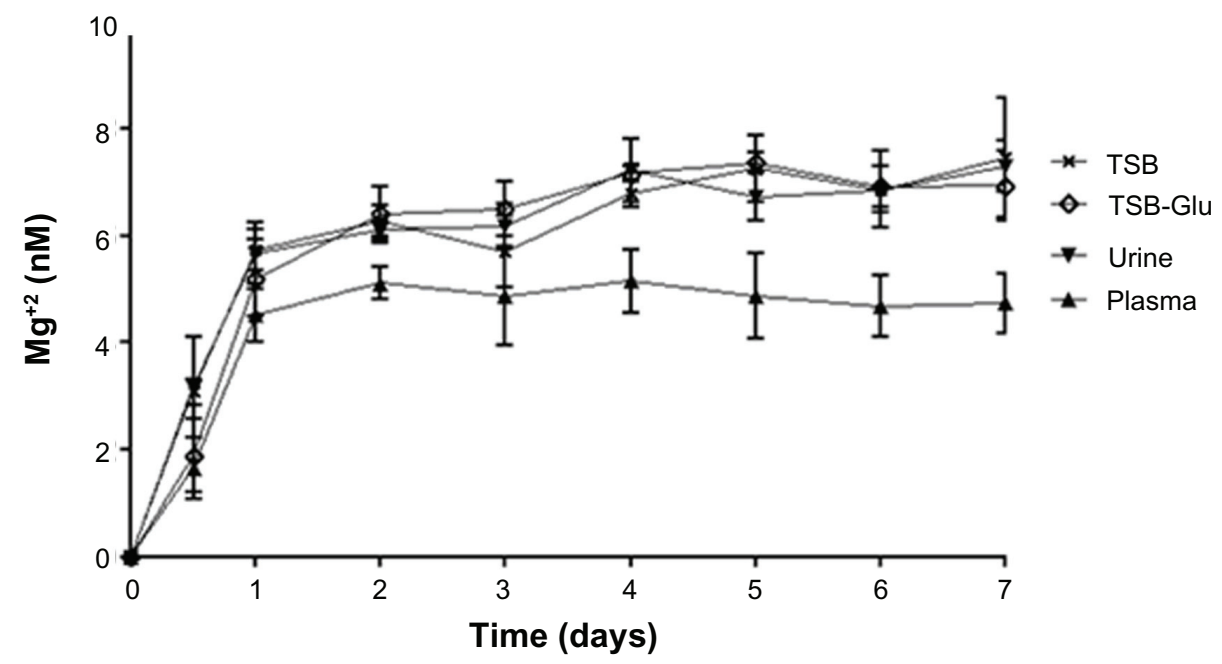

Figure 5 Amount of $\mathrm{Mg}^{+2}$ released over time from $\mathrm{MgF}_{2}$ NP-coated catheters. Coated catheters were incubated for 7 days in various fluids (TSB, TSB-Glu, urine and plasma) as described in the experimental section. The $\mathrm{Mg}^{+2}$ released from the coating of the $(\mathbf{A})$ external wall and the $(\mathbf{B})$ internal wall are presented.The $\mathbf{M g}^{+2}$ concentration released following the incubation was determined by the difference in the $\mathrm{Mg}^{+2}$ concentration present in normal levels in TSB, TSB-Glu, urine, plasma and the concentrations measured at each time point.

Note: Data represent the mean \pm SD values of three independent experiments conducted in triplicate.

Abbreviations: Glu, glucose; NP, nanoparticle; SD, standard deviation; TSB, tryptic soy broth.

\section{Antibiofilm properties of $\mathrm{MgF}_{2} \mathrm{NP}$ - coated catheters}

In a previous study, we showed that $\mathrm{MgF}_{2} \mathrm{NP}$ coating effectively inhibited the bacterial adhesion and biofilm formation of two common biofilm-forming pathogens, S. aureus (Grampositive) and E. coli (Gram-negative) for 7 days, as compared to the uncoated control. ${ }^{28}$ Considering these encouraging results, the effectiveness of $\mathrm{MgF}_{2} \mathrm{NP}$-coated catheters to inhibit bacterial colonization was further examined.

First, we tested the antibiofilm activity using standard growth media, (TSB and TSB-Glu for E. coli and S. aureus, respectively) biofilms were grown for 7 days and biofilm biomass was determined by either viable counts or $\mathrm{CV}$ staining
(Tables 1 and 2). The coating on both the internal and external walls resulted in a $100 \%$ decrease in biofilm formation for both $E$. coli and $S$. aureus after 24 hours, compared to the uncoated surface (Tables 1 and 2). Differences in reduction between the bacterial species and between the internal and external walls were seen to start at day 3 and continued until day 7 . By day 7 , a $43 \%$ reduction in $E$. coli biofilm viability on the outside wall, and a $65 \%$ reduction in the inside wall, were still observed (Table 1). S. aureus showed more promising results, with a $66 \%$ reduction in biofilm viability on the outside wall and a $79 \%$ decrease in the inside wall (Table 2).

Next, we examined the impact of biological fluids on the antibiofilm activity of these coated catheters. Urine is 
Table I Antibiofilm properties of the catheter walls coated with $\mathrm{MgF}_{2} \mathrm{NP}$ against Escherichia coli biofilm formation

\begin{tabular}{|c|c|c|c|c|c|c|c|}
\hline \multirow[t]{2}{*}{ Media } & \multirow[t]{2}{*}{ Time (days) } & \multicolumn{3}{|c|}{ Viable count } & \multicolumn{3}{|c|}{ Biofilm biomass } \\
\hline & & $\mathrm{MgF}_{2} \mathrm{NP}_{\text {coating }}$ & $\mathbf{N} / \mathbf{N}_{0}$ & $\begin{array}{c}\text { Reduction } \\
\text { (\%) }\end{array}$ & $\begin{array}{c}\text { Uncoated } \\
\left(\mathrm{OD}_{595} / \mathrm{cm}^{2}\right)\end{array}$ & $\begin{array}{c}\mathrm{MgF}_{2} \text { NP coating } \\
\left(\mathrm{OD}_{595} / \mathrm{cm}^{2}\right)\end{array}$ & $\begin{array}{c}\text { Reduction } \\
(\%)\end{array}$ \\
\hline \multicolumn{8}{|c|}{ Outside wall } \\
\hline \multirow[t]{3}{*}{ TSB } & 1 & $2.1( \pm 0.12) \times 10^{3}$ & $1.4( \pm 0.08) \times 10^{-6}$ & $\sim 100$ & $0.465( \pm 0.18)$ & $0.002( \pm 0.00)$ & $\sim 100$ \\
\hline & 3 & $3.9( \pm 0.03) \times 10^{9}$ & $1.3( \pm 0.05) \times 10^{-2}$ & 86 & $0.671( \pm 0.11)$ & $0.62( \pm 0.12)$ & 46 \\
\hline & 7 & $3.2( \pm 0.01) \times 10^{10}$ & $5.2( \pm 0.01) \times 10^{-2}$ & 43 & $0.832( \pm 0.14)$ & $0.536( \pm 0.08)$ & 20 \\
\hline \multirow[t]{3}{*}{ Urine } & 1 & $3.8( \pm 0.15) \times 10^{2}$ & $7.4( \pm 0.11) \times 10^{-5}$ & $\sim 100$ & $0.243( \pm 0.09)$ & $0.004( \pm 0.00)$ & $\sim 100$ \\
\hline & 3 & $1.5( \pm 0.08) \times 10^{7}$ & $3.1( \pm 0.03) \times 10^{-2}$ & 68 & $0.356( \pm 0.14)$ & $0.213( \pm 0.08)$ & 40 \\
\hline & 7 & $1.0( \pm 0.01) \times 10^{9}$ & $5.2( \pm 0.12) \times 10^{-2}$ & 45 & $0.447( \pm 0.17)$ & $0.348( \pm 0.11)$ & 22 \\
\hline \multirow[t]{3}{*}{ Plasma } & 1 & $1.0( \pm 0.03) \times 10^{4}$ & $1.6( \pm 0.02) \times 10^{-2}$ & 84 & $0.108( \pm 0.14)$ & $0.001( \pm 0.00)$ & $\sim 100$ \\
\hline & 3 & I.I $( \pm 0.05) \times 10^{5}$ & $6.4( \pm 0.22) \times 10^{-2}$ & 31 & $0.223( \pm 0.08)$ & $0.17 \mid( \pm 0.15)$ & 23 \\
\hline & 7 & $5.8( \pm 0.02) \times 10^{6}$ & $8.4( \pm 0.11) \times 10^{-2}$ & 15 & $0.299( \pm 0.20)$ & $0.269( \pm 0.12)$ & 10 \\
\hline \multicolumn{8}{|c|}{ Inside wall } \\
\hline \multirow[t]{3}{*}{ TSB } & 1 & $6.1( \pm 0.01) \times 10^{2}$ & $4.6( \pm 0.02) \times 10^{-5}$ & $\sim 100$ & $0.422( \pm 0.08)$ & $0.002( \pm 0.04)$ & $\sim 100$ \\
\hline & 3 & $3.1( \pm 0.03) \times 10^{8}$ & $5.0( \pm 0.13) \times 10^{-3}$ & 95 & $0.543( \pm 0.15)$ & $0.260( \pm 0.14)$ & 52 \\
\hline & 7 & $1.0( \pm 0.18) \times 10^{10}$ & $3.2( \pm 0.09) \times 10^{-2}$ & 65 & $0.654( \pm 0.11)$ & $0.601( \pm 0.10)$ & 18 \\
\hline \multirow[t]{3}{*}{ Urine } & 1 & $4.3( \pm 0.04) \times 10^{2}$ & $3.5( \pm 0.02) \times 10^{-4}$ & $\sim 100$ & $0.265( \pm 0.13)$ & $0.001( \pm 0.00)$ & $\sim 100$ \\
\hline & 3 & $2.5( \pm 0.08) \times 10^{6}$ & I.I $( \pm 0.17) \times 10^{-2}$ & 88 & $0.376( \pm 0.08)$ & $0.203( \pm 0.08)$ & 46 \\
\hline & 7 & $5.9( \pm 0.03) \times 10^{7}$ & $4.5( \pm 0.05) \times 10^{-2}$ & 54 & $0.321( \pm 0.07)$ & $0.256( \pm 0.17)$ & 20 \\
\hline \multirow[t]{3}{*}{ Plasma } & 1 & $2.4( \pm 0.04) \times 10^{4}$ & I.I $( \pm 0.03) \times 10^{-2}$ & 85 & $0.098( \pm 0.04)$ & $0.002( \pm 0.00)$ & $\sim 100$ \\
\hline & 3 & $1.6( \pm 0.02) \times 10^{6}$ & $5.5( \pm 0.12) \times 10^{-2}$ & 43 & $0.154( \pm 0.13)$ & $0.143( \pm 0.11)$ & 17 \\
\hline & 7 & $6.2( \pm 0.05) \times 10^{6}$ & $7.5( \pm 0.11) \times 10^{-2}$ & 24 & $0.222( \pm 0.16)$ & $0.202( \pm 0.05)$ & 9 \\
\hline
\end{tabular}

Notes: Biofilm biomass quantification and viable count of the biofilm cells of $E$. coli grown in TSB, urine, and plasma. The outside and inside walls of MgF ${ }_{2} \mathrm{NP}$-coated catheter incubated for 7 days at $37^{\circ} \mathrm{C}$. Uncoated catheters served as the negative control and $\mathrm{N} / \mathrm{N}_{0}$ is the relative reduction in biofilm viability fraction. Values in parentheses represent the standard deviation of three independent experiments conducted in triplicates. The results were found to be statistically significant $(P<0.05)$ between $\mathrm{MgF}_{2} \mathrm{NP}$-coated versus uncoated catheters in all treatments.

Abbreviations: NP, nanoparticle; TSB, tryptic soy broth.

known to contain an assortment of inorganic salts and organic compounds, including proteins, hormones, and a wide range of metabolites. In theory, a reduction of the antibiofilm properties would be expected, mainly due to the production of a conditioning film, but the $\mathrm{MgF}_{2} \mathrm{NP}$-coated catheters maintained fairly high antibiofilm properties. Interestingly, the biofilm development of E. coli and $S$. aureus in urine was still reduced by $100 \%$ in 24 hours on both the inside and outside walls (Tables 1 and 2). The coating maintained its antibiofilm activity even after 7 days. $S$. aureus displayed a $56 \%$ reduction in viability on the outside wall and $52 \%$ reduction on the inside wall, compared to the uncoated samples (Table 2), while E. coli biofilm viability was reduced by $45 \%$ and $54 \%$ on the outside and inside walls, respectively (Table 1).

We then examined the antibiofilm activity of the coated catheters exposed to plasma. Plasma is very rich in circulating plasma proteins, including immunoglobulins, complement proteins, fibronectin, and more. ${ }^{42}$ As described above, these proteins associated with dead cells may provide a conditioning film that may reduce the antibiofilm activity by providing a protective barrier between the surface and the bacteria.
Interestingly, the coated catheters were still able to reduce the ability of bacteria to colonize the catheter surface. After 24 hours, E. coli biofilm viability on the outside wall was reduced by $84 \%$ and by $85 \%$ on the inside wall, compared to the non-coated samples. $S$. aureus biofilm viability was reduced by $76 \%$ on both the inside and outside walls after 24 hours. On day 7, the reduction on the outside wall of both E. coli and $S$. aureus biofilm viability was approximately $16 \%$, and the inside wall showed a reduction of approximately $20 \%$ in both bacteria.

As stated above we also utilized crystal violet staining to quantify the biofilm biomass that developed on coated and uncoated catheters. As seen in Tables 1 and 2, a similar trend was observed under all tested conditions and the results correlate nicely with the viable cell counts (Tables 1 and 2).

To exclude the possibility that magnesium or fluorine ions released from the catheter walls are responsible for the antibiofilm activity observed, the following control experiments were conducted. We dissolved separately two magnesium and fluoride acetate precursor salts in water to obtain a $\mathrm{Mg}^{+2}(\mathrm{aq})$ or $\mathrm{F}^{-}(\mathrm{aq})$ concentration, which is a 100 times higher 
Table 2 Antibiofilm properties of the catheter walls coated with $\mathrm{MgF}_{2} \mathrm{NP}$ against Staphyloccocus aureus biofilm formation

\begin{tabular}{|c|c|c|c|c|c|c|c|}
\hline \multirow[t]{2}{*}{ Media } & \multirow[t]{2}{*}{ Time (days) } & \multicolumn{3}{|c|}{ Viable count } & \multicolumn{3}{|c|}{ Biofilm biomass } \\
\hline & & $\mathrm{MgF}_{2}$ NP coating & $\mathbf{N} / \mathbf{N}_{0}$ & $\begin{array}{c}\text { Reduction } \\
(\%)\end{array}$ & $\begin{array}{l}\text { Uncoated } \\
\left(\mathrm{OD}_{595} / \mathrm{cm}^{2}\right)\end{array}$ & $\begin{array}{c}\mathrm{MgF}_{2} \text { NP coating } \\
\left(\mathrm{OD}_{595} / \mathrm{cm}^{2}\right)\end{array}$ & $\begin{array}{c}\text { Reduction } \\
\text { (\%) } \\
\end{array}$ \\
\hline \multicolumn{8}{|c|}{ Outside wall } \\
\hline \multirow[t]{3}{*}{ TSB-Glu } & 1 & $2.1( \pm 0.12) \times 10^{3}$ & $1.4( \pm 0.08) \times 10^{-6}$ & $\sim 100$ & $0.132( \pm 0.10)$ & $0.001( \pm 0.00)$ & $\sim 100$ \\
\hline & 3 & $3.9( \pm 0.03) \times 10^{9}$ & $1.3( \pm 0.05) \times 10^{-2}$ & 86 & $0.343( \pm 0.12)$ & $0.113( \pm 0.05)$ & 67 \\
\hline & 7 & $3.2( \pm 0.01) \times 10^{10}$ & $5.2( \pm 0.01) \times 10^{-2}$ & 43 & $0.512( \pm 0.02)$ & $0.343( \pm 0.11)$ & 33 \\
\hline \multirow[t]{3}{*}{ Urine } & 1 & $3.8( \pm 0.15) \times 10^{2}$ & $7.4( \pm 0.11) \times 10^{-5}$ & $\sim 100$ & $0.143( \pm 0.13)$ & $0.001( \pm 0.00)$ & $\sim 100$ \\
\hline & 3 & $1.5( \pm 0.08) \times 10^{7}$ & $3.1( \pm 0.03) \times 10^{-2}$ & 68 & $0.288( \pm 0.09)$ & $0.095( \pm 0.13)$ & 67 \\
\hline & 7 & $1.0( \pm 0.01) \times 10^{9}$ & $5.2( \pm 0.12) \times 10^{-2}$ & 45 & $0.443( \pm 0.15)$ & $0.349( \pm 0.09)$ & 21 \\
\hline \multirow[t]{3}{*}{ Plasma } & 1 & $1.0( \pm 0.03) \times 10^{4}$ & $1.6( \pm 0.02) \times 10^{-2}$ & 84 & $0.092( \pm 0.13)$ & $0.002( \pm 0.03)$ & $\sim 100$ \\
\hline & 3 & I.I $( \pm 0.05) \times 10^{5}$ & $6.4( \pm 0.22) \times 10^{-2}$ & 31 & $0.155( \pm 0.11)$ & $0.008( \pm 0.1 \mathrm{I})$ & 43 \\
\hline & 7 & $5.8( \pm 0.02) \times 10^{6}$ & $8.4( \pm 0.11) \times 10^{-2}$ & 15 & $0.221( \pm 0.05)$ & $0.201( \pm 0.08)$ & 19 \\
\hline \multicolumn{8}{|c|}{ Inside wall } \\
\hline \multirow[t]{3}{*}{ TSB-Glu } & I & $6.1( \pm 0.01) \times 10^{2}$ & $4.6( \pm 0.02) \times 10^{-5}$ & $\sim 100$ & $0.154( \pm 0.14)$ & $0.003( \pm 0.01)$ & $\sim 100$ \\
\hline & 3 & $3.1( \pm 0.03) \times 10^{8}$ & $5.0( \pm 0.13) \times 10^{-3}$ & 95 & $0.388( \pm 0.02)$ & $0.135( \pm 0.11)$ & 65 \\
\hline & 7 & $1.0( \pm 0.18) \times 10^{10}$ & $3.2( \pm 0.09) \times 10^{-2}$ & 65 & $0.587( \pm 0.08)$ & $0.369( \pm 0.13)$ & 37 \\
\hline \multirow[t]{3}{*}{ Urine } & 1 & $4.3( \pm 0.04) \times 10^{2}$ & $3.5( \pm 0.02) \times 10^{-4}$ & $\sim 100$ & $0.154( \pm 0.16)$ & $0.000( \pm 0.00)$ & $\sim 100$ \\
\hline & 3 & $2.5( \pm 0.08) \times 10^{6}$ & I.I $( \pm 0.17) \times 10^{-2}$ & 88 & $0.308( \pm 0.05)$ & $0.095( \pm 0.10)$ & 69 \\
\hline & 7 & $5.9( \pm 0.03) \times 10^{7}$ & $4.5( \pm 0.05) \times 10^{-2}$ & 54 & $0.455( \pm 0.13)$ & $0.236( \pm 0.14)$ & 48 \\
\hline \multirow[t]{3}{*}{ Plasma } & 1 & $2.4( \pm 0.04) \times 10^{4}$ & I.I $( \pm 0.03) \times 10^{-2}$ & 85 & $0.087( \pm 0.14)$ & $0.001( \pm 0.02)$ & $\sim 100$ \\
\hline & 3 & $1.6( \pm 0.02) \times 10^{6}$ & $5.5( \pm 0.12) \times 10^{-2}$ & 43 & $0.134( \pm 0.01)$ & $0.088( \pm 0.12)$ & 34 \\
\hline & 7 & $6.2( \pm 0.05) \times 10^{6}$ & $7.5( \pm 0.11) \times 10^{-2}$ & 24 & $0.265( \pm 0.15)$ & $0.212( \pm 0.11)$ & 20 \\
\hline
\end{tabular}

Notes: Biofilm biomass quantification and viable count of the biofilm cells of S. aureus grown in TSB-Glu, urine, and plasma. The outside and inside walls of MgF ${ }_{2}$ NP-coated catheter incubated for 7 days at $37^{\circ} \mathrm{C}$. Uncoated catheters served as the negative control and $\mathrm{N} / \mathrm{N}_{0}$ is the relative reduction in biofilm viability fraction. Values in parentheses represent the standard deviation of three independent experiments conducted in triplicates. The results were found to be statistically significant $(P<0.05)$ between $\mathrm{MgF}_{2}$ NP-coated versus uncoated catheters in all treatments.

Abbreviations: Glu, glucose; NP, nanoparticle; TSB, tryptic soy broth.

than the expected concentration of these ions based on the solubility of $\mathrm{MgF}_{2}$ in water. The results show that even at these higher concentrations, the ions are not able to cause a similar inhibition in biofilm formation (Tables S1 and S2). Taken together, these results strongly suggest that the nanometric properties of $\mathrm{MgF}_{2}$ are responsible for the antibiofilm activity, and not the dissolved ions. This is also supported by our previous work. ${ }^{27}$

\section{Biocompatibility of $\mathrm{MgF}_{2} \mathrm{NP}$-coated catheters}

The potential use of NPs in various medical applications raises the need to examine the potential cytotoxicity effect of these agents. Despite the rapid progress of nanotechnology, the potential of adverse health affects due to prolonged exposure to nanomaterials has yet to be thoroughly investigated. Silver NPs, for example, have gained much popularity recently owing to their broad-spectrum antimicrobial activity. ${ }^{24,43,44}$ However, recent in vivo reports have established that exposure to silver NPs may induce severe side effects, including changes in lung function; increase in inflammation; and activation of a mitochondria-dependent, stress-activated protein kinase pathway. ${ }^{45}$ In addition, the induction of distinct developmental defects in zebrafish embryos has been reported in response to exposure to silver NPs. ${ }^{46}$ To begin to evaluate the potential or $\mathrm{MgF}_{2} \mathrm{NPs}$-coated catheters to exert cytotoxicity, we conducted MTT viability measurements on HeLa, HEK 293, and MEFs cell lines exposed to coated and uncoated catheters (Table 3). In HeLa cells less than $20 \%$ reduction in the mitochondrial activity was observed upon exposure to $\mathrm{MgF}_{2} \mathrm{NP}$-coated catheters, compared to the mitochondrial activity of cells grown on uncoated catheters (Table 3 ). The same trend was also observed with the HEK 293 and MEFs cell lines and no significant reduction was measured (from $15 \%$ to $5 \%$ for MEFs and HEK 293, respectively).

We confirmed these results by fluorescence microscopy using HeLa cells. As depicted in Figure 6, no changes in cell morphology, size and membrane symmetry were observed in cells grown on $\mathrm{MgF}_{2} \mathrm{NP}$-coated surfaces. In addition, no sign of apoptosis such as the appearance of apoptotic bodies was observed. Furthermore, fluorescent microscopy was used to evaluate a potential process of programmed cell death; 
Table 3 Cytotoxicity of $\mathrm{MgF}_{2}$ NP-coated catheter on mitochondrial activity

\begin{tabular}{|c|c|c|c|}
\hline & $\begin{array}{c}\text { Uncoated } \\
\left(O_{570}\right) \\
\end{array}$ & $\begin{array}{c}M g F_{2} \text { NP-coated } \\
\left(O_{570}\right)\end{array}$ & $\begin{array}{c}\text { Variation } \\
\text { in viability (\%) }\end{array}$ \\
\hline HeLa & $0.765( \pm 0.19)$ & $0.634( \pm 0.09)$ & -17 \\
\hline HEK 293 & $0.365( \pm 0.08)$ & $0.348( \pm 0.01)$ & -5 \\
\hline MEFs & $0.688( \pm 0.11)$ & $0.583( \pm 0.10)$ & -15 \\
\hline
\end{tabular}

Notes: MTT viability measurements of HeLa, HEK 293, and MEFs cells grown on uncoated and $\mathrm{MgF}_{2} \mathrm{NP}$-coated catheter for 24 hours. Data collected from the optical density of the formazan at $570 \mathrm{~nm}\left(O D_{570}\right)$. Values in parentheses represent the standard deviation of three independent experiments conducted in triplicates. The results were found to be statistically significant $(P<0.05)$ between $\mathrm{MgF}_{2} \mathrm{NP}-$ coated versus uncoated catheters in all treatments.

Abbreviations: HEK, human embryonic kidney; MEFs, mouse embryonic fibroblasts; MTT, 3-(4,5-Dimethylthiazol-2-yl)-2,5-diphenyltetrazolium bromide; NP, nanoparticle.

$\beta$-tubulin staining showed that the cytoskeleton of cells grown on $\mathrm{MgF}_{2} \mathrm{NP}$-coated catheters had the same phenotype as the control cells grown on uncoated catheters (Figure 6). DNA staining was also conducted and no nuclear fragmentation, chromatin condensation, or chromosomal DNA fragmentations were observed (Figure 6). Taken together, these preliminary results support further testing of the tolerance and cytotoxicity of the $\mathrm{MgF}_{2}$ NP-coated surfaces, and emphasize the potential of using these NPs for various medical applications.

\section{Conclusion}

The present study presents the synthesis and coating of crystalline $\mathrm{MgF}_{2} \mathrm{NP}$ on catheters using a simple sonochemical process. Our results revealed that this ultrasonic synthesis

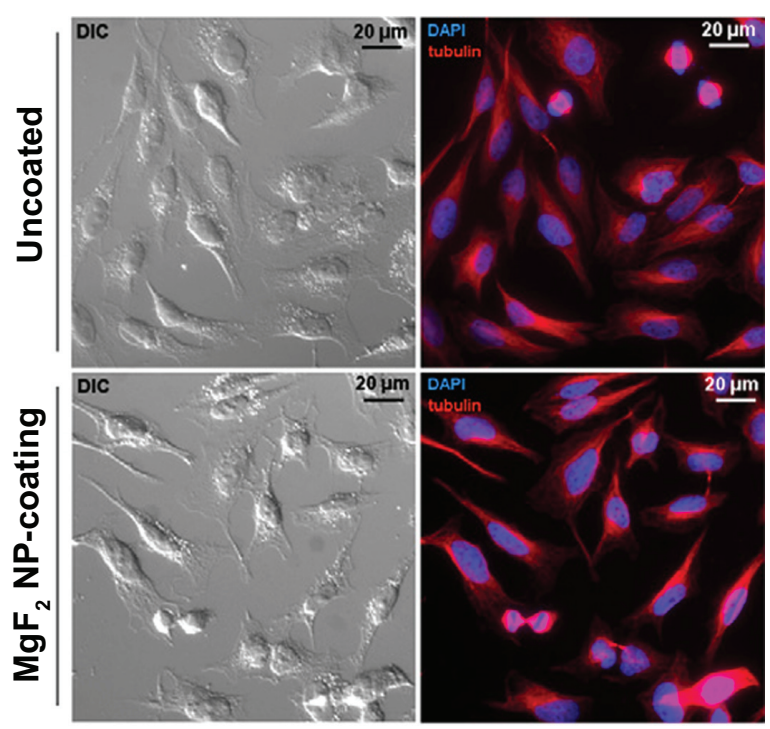

Figure 6 Biocompatibility of $\mathrm{MgF}_{2} \mathrm{NP}$-coated catheters. Left column: DIC imaging of HeLa cells grown on uncoated and $\mathrm{MgF}_{2} \mathrm{NP}$-coated catheters for 24 hours. Right column: Fluorescence microscopy overlay of the DNA (blue) and $\beta$-tubulin (red) of the same cells imaged by DIC.

Abbreviations: DIC, differential interference contrast; NP, nanoparticle. provides a stable and antibiofilm active coating. The $\mathrm{MgF}_{2}$ NP coating is homogenous and is present on both the internal and external sides of the catheter. The coated catheters effectively restricted biofilm formation in both growth media and biologically relevant fluids (human plasma and urine). In addition, the preliminary biocompatibility assays suggest no major adverse effects on human cell lines. Taken together, the results of this study emphasize the potential use of $\mathrm{MgF}_{2} \mathrm{NPs}$ as a new approach for the design of sterile surface coatings that may be useful for various medical applications.

\section{Acknowledgments}

We thank Dr Gal Yerushalmi for her helpful discussion and critical review of the manuscript. This research was carried out as part of the activities of the KAMIN project financed by the Israeli Ministry of Industry. This research is part of the requirements for a $\mathrm{PhD}$ thesis for Jonathan Lellouche at Bar Ilan University. We confirm that the manuscript has been read and approved by all named authors and that there are no other persons who satisfied the criteria for authorship that are not listed. We further confirm that the order of authors listed in the manuscript has been approved by all of us.

\section{Disclosure}

We confirm that there are no known conflicts of interest associated with this publication and there has been no significant financial support for this work that could have influenced its outcome.

\section{References}

1. Mack D, Rohde H, Harris LG, et al. Biofilm formation in medical device-related infection. Int J Artifi Organs. 2006;29(4):343-359.

2. Darouiche RO. Treatment of infections associated with surgical implants. New Engl J Med. 2004;350(14):1422-1429.

3. Trautner BW, Darouiche RO. Role of biofilm in catheter-associated urinary tract infection. Am J Infect Control. 2004;32(3):177-183.

4. Trautner BW, Darouiche RO. Catheter-associated infections: pathogenesis affects prevention. Arch Intern Med. 2004;164(8):842-850.

5. Costerton JW, Stewart PS, Greenberg EP. Bacterial biofilms: a common cause of persistent infections. Science. 1999;284(5418):1318-1322.

6. Mermel LA, Farr BM, Sherertz RJ, et al. Guidelines for the management of intravascular catheter-related infections. $J$ Intraven Nurs. 2001;24(3):180-205.

7. Rosenthal VD, Maki DG, Salomao R, et al. Device-associated nosocomial infections in 55 intensive care units of 8 developing countries. Ann Intern Med. 2006;145(8):582-591.

8. Randolph AG, Brun-Buisson C, Goldmann D. Identification of central venous catheter-related infections in infants and children. Pediatr Crit Care Med. 2005;6(3):S19-S24.

9. Kline AM. Pediatric catheter-related bloodstream infections: latest strategies to decrease risk. AACN Clin Issues. 2005;16(2):185-198; quiz 272-274.

10. National Nosocomial Infections Surveillance System. National Nosocomial Infections Surveillance (NNIS) System Report, data summary from January 1992 through June 2004, issued October 2004. Am J Infect Control. 2004;32(8):470-485. 
11. Foxman B. The epidemiology of urinary tract infection. Nat Rev Urol. 2010;7(12):653-660.

12. Johnson JR, Kuskowski MA, Wilt TJ. Systematic review: antimicrobial urinary catheters to prevent catheter-associated urinary tract infection in hospitalized patients. Ann Intern Med. 2006;144(2):116-126.

13. Sandhiya S, Dkhar SA, Surendiran A. Emerging trends of nanomedicine - an overview. Fundam Clin Pharmacol. 2009;23(3): 263-269.

14. Vasilev K, Cook J, Griesser HJ. Antibacterial surfaces for biomedical devices. Expert Rev Med Devices. 2009;6(5):553-567.

15. Hanna H, Darouiche R, Raad I. New approaches for prevention of intravascular catheter-related infections. Infect Med. 2001;18(1):38-48.

16. Applerot G, Perkas N, Amirian G, Girshevitz O, Gedanken A. Coating of glass with $\mathrm{ZnO}$ via ultrasonic irradiation and a study of its antibacterial properties. Appl Surf Sci. 2009;256:S3-S8.

17. Applerot G, Abu-Mukh R, Irzh A, et al. Decorating parylene-coated glass with $\mathrm{ZnO}$ nanoparticles for antibacterial applications: a comparative sudy of sonochemical, microwave, and microwave-plasma coating routes. ACS Apll Mater Interfaces. 2010;2(4):1052-1059.

18. Roe D, Karandikar B, Bonn-Savage N, Gibbins B, Roullet JB. Antimicrobial surface functionalization of plastic catheters by silver nanoparticles. J Antimicrob Chemother. 2008;61(4):869-876.

19. Samuel U, Guggenbichler JP. Prevention of catheter-related infections: the potential of a new nano-silver impregnated catheter. Int J Antimicrob Agents. 2004;23 Suppl 1:S75-S78.

20. Chaiban G, Hanna H, Dvorak T, Raad I. A rapid method of impregnating endotracheal tubes and urinary catheters with gendine: a novel antiseptic agent. J Antimicrob Chemother. 2005;55(1):51-56.

21. Bahna BN, Hanna HA, Dvorak T, et al. Gendine coated orthopedic metal devices (OMDs) for the prevention of bacterial infections. Abstracts of the 45th Interscience Conference on Antimicrobial Agents and Chemotherapy, Washington, DC, 2005:322.

22. Stevens KN, Croes S, Boersma RS, et al. Hydrophilic surface coatings with embedded biocidal silver nanoparticles and sodium heparin for central venous catheters. Biomaterials. 2011;32(5):1264-1269.

23. Ahamed M, AlSalhi MS, Siddiqui MKJ. Silver nanoparticle applications and human health. Clin Chim Acta. 2010;411(23-24):1841-1848.

24. Ahamed M, Posgai R, Gorey TJ, et al. Silver nanoparticles induced heat shock protein 70, oxidative stress and apoptosis in Drosophila melanogaster. Toxicol Appl Pharmacol. 2010;242(3): 263-269.

25. Environmental Protection Agency. Silver (CASRN 7440-7422-4), 1996.

26. Fung MC, Bowen DL. Silver products for medical indications: Riskbenefit assessment. J Toxicol Clin Toxicol. 1996;34(1):119-126.

27. Lellouche J, Kahana E, Elias S, Gedanken A, Banin E. Antibiofilm activity of nanosized magnesium fluoride. Biomaterials. 2009; 30(30):5969-5978.

28. Lellouche J, Friedman A, Lellouche JP, Gedanken A, Banin E. Improved antibacterial and antibiofilm activity of magnesium fluoride nanoparticles obtained by water-based ultrasound chemistry. Nanomedicine. 2011. Epub Sep 21.
29. Shanks RM, Donegan NP, Graber ML, et al. Heparin stimulates Staphylococcus aureus biofilm formation. Infect Immun. 2005;73(8): 4596-4606.

30. Dewanti R, Wong AC. Influence of culture conditions on biofilm formation by Escherichia coli O157:H7. Int J Food Microbiol. 1995; 26(2):147-164.

31. Antunes AL, Trentin DS, Bonfanti JW, et al. Application of a feasible method for determination of biofilm antimicrobial susceptibility in staphylococci. APMIS. 2010;118(11):873-877.

32. Park KD, Kim YS, Han DK, et al. Bacterial adhesion on PEG modified polyurethane surfaces. Biomaterials. 1998;19(7):851-859.

33. Kadurugamuwa JL, Sin L, Albert E, et al. Direct continuous method for monitoring biofilm infection in a mouse model. Infect Immun. 2003;71(2):882-890.

34. Jones CA. Central venous catheter infection in adults in acute hospital settings. Br J Nurs. 2006;15(7):362, 364-368.

35. Mosmann T. Rapid Colorimetric assay for cellular growth and survival: application to proliferation and cytotoxicity assays. J Immunol Methods. 1983;65(1-2):55-63.

36. Soloviev M, Gedanken A. Coating a stainless steel plate with silver nanoparticles by the sonochemical method. Ultrason Sonochem. 2011; 18(1):356-362.

37. Angel U, Silva CM, Cavaco-Paulo A, et al. Attaching different kinds of proteinaceous nanospheres to a variety of fabrics using ultrasound radiation. Israel J Chem. 2010;50:524-529.

38. Gedanken A, Mastai Y, editors. Sonochemistry and other novel methods developed for the synthesis of nanoparticles. In: Rao CN, Achim Mueller HC, Cheetham AK. The Chemistry of Nanomaterials: Synthesis, Properties and Applications. Wiley-VCH Verlag GmbH \& Co. KGaA. 2005:113-169.

39. Suslick KS. The chemical effects of ultrasound. Scientific American. 1989;260:(2)80-86.

40. Perelshtein I, Applerot G, Perkas N, et al. Ultrasound radiation as a "throwing stones" technique for the production of antibacterial nanocomposite textiles. ACS Appl Mater Interfaces. 2010;2(7):1999-2004.

41. Odian G. Principles of Polymerization. 4th ed. Wiley-VCH Verlag $\mathrm{GmbH}$ and Co. KGaA. 2004.

42. Schaller J, Gerber S, Kämpfer U, Lejon S, Trachsel C. Blood components. In: Human Blood Plasma Proteins: Structure and Function. Chichester: John Wiley \& Sons Ltd; 2008:17-20.

43. Lok CN, Ho CM, Chen R, et al. Proteomic analysis of the mode of antibacterial action of silver nanoparticles. J Proteome Res. 2006;5(4): 916-924.

44. Gogoi SK, Gopinath P, Paul A, et al. Green fluorescent protein-expressing Escherichia coli as a model system for investigating the antimicrobial activities of silver nanoparticles. Langmuir. 2006;22(22):9322-9328.

45. Hsin YH, Chena CF, Huang S, et al. The apoptotic effect of nanosilver is mediated by a ROS- and JNK-dependent mechanism involving the mitochondrial pathway in NIH3T3 cells. Toxicol Lett. 2008;179(3):130-139.

46. Asharani PV, Lian Wu Y, Gong Z, Valiyaveettil S. Toxicity of silver nanoparticles in zebrafish models. Nanotechnology. 2008;19(25):255102. 


\section{Supplementary data}

\section{$\mathrm{MgF}_{2} \mathrm{NP}$ characterization}

The NP morphology and its crystalline characterization are depicted in Figure S1. The powder XRD analysis of the NPs showed a clear crystalline pattern (Figure S1A). The XRD pattern matched the reflection peaks of the tetragonal $\mathrm{MgF}_{2}$ phase (Joint Committee on Powder Diffraction Standards card No 00-041-1443) characterized by diffraction planes (110), (101), (111), (210), (211), (220), (002), (310), (301), (311), and (222). No additional diffraction peaks of any impurity were detected, demonstrating the high purity of the product. In addition, the average diameter of crystallites calculated by the Debye-Scherrer equation afforded a value of $24.8 \mathrm{~nm}$, which is similar to the average size measured by HR SEM (Figure S1B and C). The fabricated $\mathrm{MgF}_{2} \mathrm{NPs}$ showed spherical, well-shaped nanostructure morphology. Figure S1D also disclosed characteristic lattice fringes of the crystalline phase. The measured inter-fringe distance of $3.32 \AA$ matches perfectly the (110) interplanar distance (Joint Committee on Powder Diffraction Standards card No 00-041-1443).
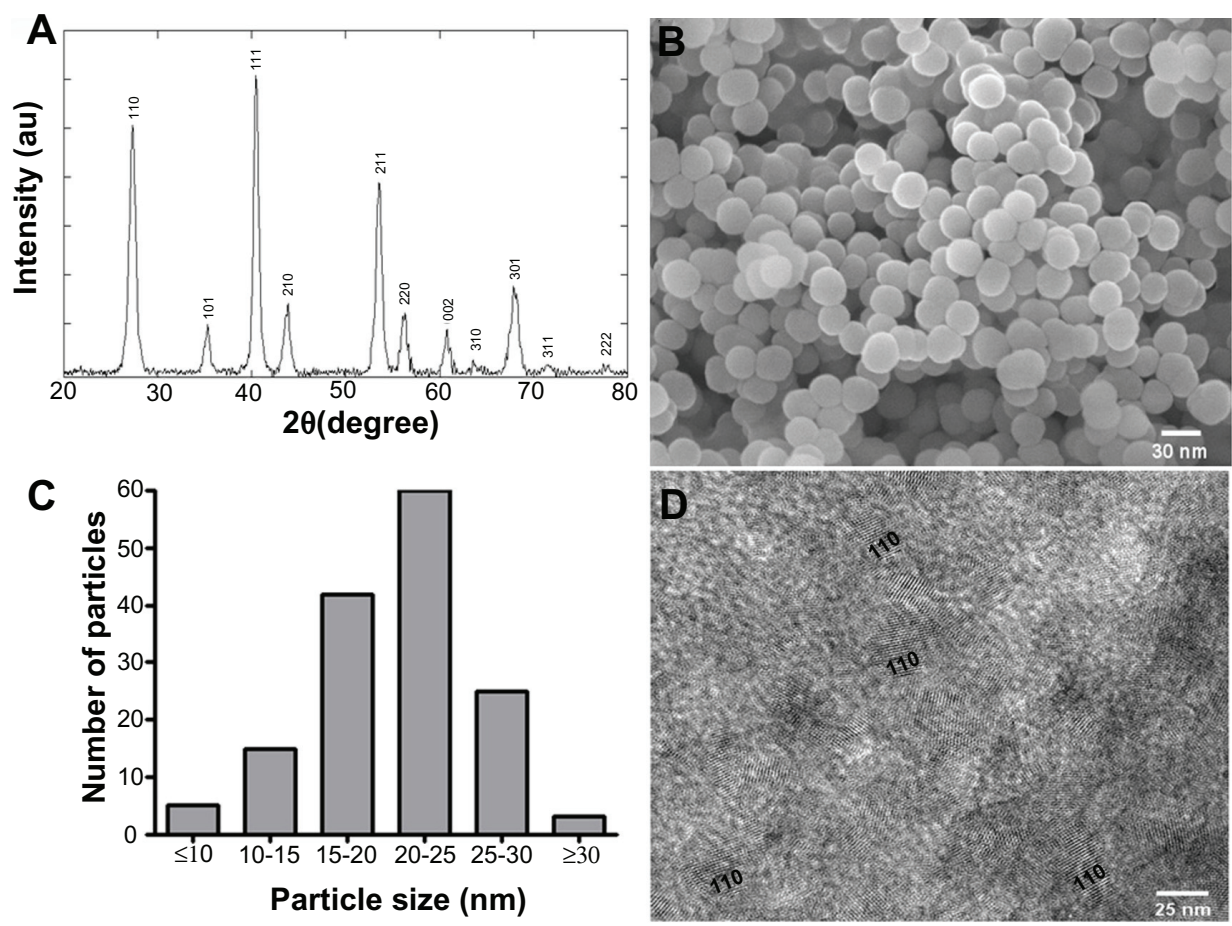

Figure $\mathrm{SI} \mathrm{MgF}_{2} \mathrm{NP}$ characterization. (A) XRD patterns of $\mathrm{MgF}_{2} \mathrm{NPs}$ with the Miller indices of the respective atomic planes; (B) HR SEM image; (C) size distribution; and (D) HR TEM micrograph of $\mathrm{MgF}_{2} \mathrm{NPs}$ and the 110 plane.

Abbreviations: HR SEM, high resolution scanning electron microscope; HR TEM, high resolution transmission electron microscope; NP, nanoparticle; XRD, X-ray diffraction. 
Table SI Influence of $\mathrm{Mg}^{+2}$ and $\mathrm{F}^{-}$on the Escherichia coli biofilm formation on the catheter walls

\begin{tabular}{|c|c|c|c|c|c|c|c|}
\hline \multirow[t]{2}{*}{ Media } & \multirow[t]{2}{*}{ Time (days) } & \multicolumn{3}{|c|}{ Biofilm biomass } & \multicolumn{3}{|c|}{ Viable count } \\
\hline & & $\begin{array}{l}\text { Medium only } \\
\left(\mathrm{OD}_{595} / \mathrm{cm}^{2}\right)\end{array}$ & $\begin{array}{c}+\mathrm{Mg}^{+2} \\
\left(O D_{595} / \mathrm{cm}^{2}\right)\end{array}$ & $\begin{array}{c}+\mathrm{F}^{-} \\
\left(\mathrm{OD}_{595} / \mathrm{cm}^{2}\right)\end{array}$ & $\begin{array}{l}\text { Medium only } \\
(\text { CFU/cm²) }\end{array}$ & $\begin{array}{c}+\mathrm{Mg}^{+2} \\
\left(\mathrm{CFU} / \mathrm{cm}^{2}\right)\end{array}$ & $\begin{array}{c}+\mathrm{F}^{-} \\
\left(\mathrm{CFU} / \mathrm{cm}^{2}\right)\end{array}$ \\
\hline \multicolumn{8}{|c|}{ Outside wall } \\
\hline \multirow[t]{3}{*}{ TSB } & 1 & $0.465( \pm 0.18)$ & $0.476( \pm 0.08)$ & $0.454( \pm 0.1 \mathrm{I})$ & $6.2( \pm 0.11) \times 10^{8}$ & 4.1 $( \pm 0.09) \times 10^{9}$ & $2.5( \pm 0.11) \times 10^{8}$ \\
\hline & 3 & $0.671( \pm 0.11)$ & $0.643( \pm 0.16)$ & $0.635( \pm 0.06)$ & $3.6( \pm 0.27) \times 10^{10}$ & $2.6( \pm 0.13) \times 10^{10}$ & $3.5( \pm 0.27) \times 10^{9}$ \\
\hline & 7 & $0.832( \pm 0.14)$ & $0.844( \pm 0.1 \mathrm{I})$ & $0.854( \pm 0.13)$ & $5.9( \pm 0.03) \times 10^{10}$ & $4.5( \pm 0.26) \times 10^{11}$ & $1.2( \pm 0.03) \times 10^{10}$ \\
\hline \multirow[t]{3}{*}{ Urine } & I & $0.243( \pm 0.09)$ & $0.256( \pm 0.19)$ & $0.244( \pm 0.09)$ & $5.2( \pm 0.12) \times 10^{6}$ & $3.6( \pm 0.42) \times 10^{6}$ & $4.0( \pm 0.12) \times 10^{6}$ \\
\hline & 3 & $0.356( \pm 0.14)$ & $0.387( \pm 0.10)$ & $0.396( \pm 0.13)$ & $6.0( \pm 0.08) \times 10^{8}$ & $7.0( \pm 0.08) \times 10^{9}$ & $7.2( \pm 0.08) \times 10^{8}$ \\
\hline & 7 & $0.447( \pm 0.17)$ & $0.466( \pm 0.07)$ & $0.470( \pm 0.17)$ & $3.1( \pm 0.02) \times 10^{9}$ & $1.1( \pm 0.11) \times 10^{9}$ & $2.0( \pm 0.02) \times 10^{10}$ \\
\hline \multirow[t]{3}{*}{ Plasma } & 1 & $0.108( \pm 0.14)$ & $0.143( \pm 0.04)$ & $0.145( \pm 0.02)$ & $6.0( \pm 0.33) \times 10^{4}$ & $2.5( \pm 0.07) \times 10^{4}$ & $1.8( \pm 0.33) \times 10^{4}$ \\
\hline & 3 & $0.223( \pm 0.08)$ & $0.203( \pm 0.04)$ & $0.233( \pm 0.14)$ & $1.7( \pm 0.32) \times 10^{4}$ & $1.4( \pm 0.16) \times 10^{7}$ & $1.94( \pm 0.32) \times 10^{6}$ \\
\hline & 7 & $0.299( \pm 0.20)$ & $0.303( \pm 0.10)$ & $0.313( \pm 0.1 \mathrm{I})$ & $6.9( \pm 0.52) \times 10^{6}$ & $3.6( \pm 0.32) \times 10^{6}$ & $2.5( \pm 0.52) \times 10^{6}$ \\
\hline \multicolumn{8}{|c|}{ Inside wall } \\
\hline \multirow[t]{3}{*}{ TSB } & I & $0.422( \pm 0.08)$ & $0.413( \pm 0.10)$ & $0.431( \pm 0.11)$ & $2.8( \pm 0.11) \times 10^{7}$ & $1.0( \pm 0.14) \times 10^{7}$ & $2.1( \pm 0.24) \times 10^{6}$ \\
\hline & 3 & $0.543( \pm 0.15)$ & $0.555( \pm 0.1 \mathrm{I})$ & $0.548( \pm 0.12)$ & $4.1( \pm 0.02) \times 10^{9}$ & $2.0( \pm 0.32) \times 10^{9}$ & $5.2( \pm 0.53) \times 10^{9}$ \\
\hline & 7 & $0.654( \pm 0.11)$ & $0.663( \pm 0.01)$ & $0.655( \pm 0.12)$ & $5.3( \pm 0.4 I) \times 10^{10}$ & $1.3( \pm 0.17) \times 10^{11}$ & $7.8( \pm 0.23) \times 10^{10}$ \\
\hline \multirow[t]{3}{*}{ Urine } & 1 & $0.265( \pm 0.13)$ & $0.276( \pm 0.12)$ & $0.231( \pm 0.13)$ & $1.2( \pm 0.12) \times 10^{6}$ & $3.6( \pm 0.12) \times 10^{6}$ & $5.6( \pm 0.36) \times 10^{6}$ \\
\hline & 3 & $0.376( \pm 0.08)$ & $0.306( \pm 0.03)$ & $0.346( \pm 0.13)$ & $5.6( \pm 0.22) \times 10^{8}$ & $7.2( \pm 0.18) \times 10^{8}$ & $3.8( \pm 0.77) \times 10^{7}$ \\
\hline & 7 & $0.321( \pm 0.07)$ & $0.333( \pm 0.17)$ & $0.357( \pm 0.14)$ & $7.8( \pm 0.36) \times 10^{8}$ & $5.2( \pm 0.44) \times 10^{8}$ & $4.7( \pm 0.02) \times 10^{8}$ \\
\hline \multirow[t]{3}{*}{ Plasma } & 1 & $0.098( \pm 0.04)$ & $0.100( \pm 0.05)$ & $0.111( \pm 0.13)$ & $3.6( \pm 0.21) \times 10^{4}$ & $4.1( \pm 0.5 \mathrm{I}) \times 10^{4}$ & $3.6( \pm 0.21) \times 10^{4}$ \\
\hline & 3 & $0.154( \pm 0.13)$ & $0.145( \pm 0.11)$ & $0.134( \pm 0.01)$ & $4.2( \pm 0.17) \times 10^{6}$ & $3.8( \pm 0.33) \times 10^{6}$ & $8.8( \pm 0.47) \times 10^{6}$ \\
\hline & 7 & $0.222( \pm 0.16)$ & $0.215( \pm 0.06)$ & $0.217( \pm 0.12)$ & $1.2( \pm 0.22) \times 10^{6}$ & $4.8( \pm 0.05) \times 10^{7}$ & $9.8( \pm 0.21) \times 10^{6}$ \\
\hline
\end{tabular}

Notes: Biofilm biomass quantification and viable count of the biofilm cells of $E$. coli grown in TSB, urine, and plasma on a catheter exposed to fluorine ( $0.5 \mathrm{mg} / \mathrm{mL})$, and magnesium ions $(0.5 \mathrm{mg} / \mathrm{mL})$. Catheters incubated for 7 days at $37^{\circ} \mathrm{C}$. Values in parentheses represent the standard deviation of three independent experiments conducted in triplicates. Abbreviation: TSB, tryptic soy broth.

Table S2 Influence of $\mathrm{Mg}^{+2}$ and $\mathrm{F}^{-}$on the Staphylococcus aureus biofilm formation on the catheter walls

\begin{tabular}{|c|c|c|c|c|c|c|c|}
\hline \multirow[t]{2}{*}{ Media } & \multirow[t]{2}{*}{ Time (days) } & \multicolumn{3}{|c|}{ Biofilm biomass } & \multicolumn{3}{|c|}{ Viable count } \\
\hline & & $\begin{array}{c}\text { Medium only } \\
\left(\mathrm{OD}_{595} / \mathrm{cm}^{2}\right)\end{array}$ & $\begin{array}{c}+\mathrm{Mg}^{+2} \\
\left(\mathrm{OD}_{595} / \mathrm{cm}^{2}\right)\end{array}$ & $\begin{array}{c}+\mathrm{F}^{-} \\
\left(\mathrm{OD}_{595} / \mathrm{cm}^{2}\right)\end{array}$ & $\begin{array}{l}\text { Medium only } \\
\left(\mathrm{CFU} / \mathrm{cm}^{2}\right)\end{array}$ & $\begin{array}{c}+\mathrm{Mg}^{+2} \\
\left(\mathrm{CFU} / \mathrm{cm}^{2}\right)\end{array}$ & $\begin{array}{c}+\mathrm{F}^{-} \\
\left(\mathrm{CFU} / \mathrm{cm}^{2}\right)\end{array}$ \\
\hline \multicolumn{8}{|c|}{ Outside wall } \\
\hline \multirow[t]{3}{*}{ TSB-Glu } & I & $0.132( \pm 0.10)$ & $0.137( \pm 0.11)$ & $0.126( \pm 0.10)$ & $3.2( \pm 0.0 \mathrm{I}) \times 10^{8}$ & $1.7( \pm 0.17) \times 10^{8}$ & $6.3( \pm 0.07) \times 10^{8}$ \\
\hline & 3 & $0.343( \pm 0.12)$ & $0.363( \pm 0.02)$ & $0.345( \pm 0.03)$ & $5.8( \pm 0.06) \times 10^{9}$ & $3.6( \pm 0.28) \times 10^{9}$ & $7.8( \pm 0.22) \times 10^{9}$ \\
\hline & 7 & $0.512( \pm 0.02)$ & $0.545( \pm 0.04)$ & $0.538( \pm 0.14)$ & $6.3( \pm 0.54) \times 10^{11}$ & $4.8( \pm 0.36) \times 10^{10}$ & $1.5( \pm 0.48) \times 10^{10}$ \\
\hline \multirow[t]{3}{*}{ Urine } & I & $0.143( \pm 0.13)$ & $0.133( \pm 0.17)$ & $0.154( \pm 0.11)$ & $8.3( \pm 0.41) \times 10^{6}$ & $6.2( \pm 0.05) \times 10^{6}$ & $3.2( \pm 0.08) \times 10^{6}$ \\
\hline & 3 & $0.288( \pm 0.09)$ & $0.256( \pm 0.1 \mathrm{I})$ & $0.276( \pm 0.13)$ & $9.1( \pm 0.36) \times 10^{7}$ & $7.1( \pm 0.16) \times 10^{7}$ & $4.2( \pm 0.63) \times 10^{8}$ \\
\hline & 7 & $0.443( \pm 0.15)$ & $0.448( \pm 0.12)$ & $0.421( \pm 0.12)$ & $5.6( \pm 0.74) \times 10^{9}$ & $7.1( \pm 0.25) \times 10^{10}$ & $3.8( \pm 0.23) \times 10^{10}$ \\
\hline \multirow[t]{3}{*}{ Plasma } & I & $0.092( \pm 0.13)$ & $0.100( \pm 0.11)$ & $0.099( \pm 0.01)$ & $2.6( \pm 0.25) \times 10^{4}$ & $2.5( \pm 0.36) \times 10^{4}$ & $4.8( \pm 0.74) \times 10^{4}$ \\
\hline & 3 & $0.155( \pm 0.11)$ & $0.145( \pm 0.01)$ & $0.156( \pm 0.16)$ & $4.6( \pm 0.47) \times 10^{5}$ & $3.6( \pm 0.17) \times 10^{5}$ & $8.1( \pm 0.03) \times 10^{6}$ \\
\hline & 7 & $0.221( \pm 0.05)$ & $0.232( \pm 0.15)$ & $0.220( \pm 0.11)$ & $5.2( \pm 0.36) \times 10^{5}$ & $7.5( \pm 0.48) \times 10^{5}$ & $2.3( \pm 0.33) \times 10^{5}$ \\
\hline \multicolumn{8}{|c|}{ Inside wall } \\
\hline \multirow[t]{3}{*}{ TSB-Glu } & I & $0.465( \pm 0.18)$ & $0.454( \pm 0.1 \mathrm{I})$ & $0.460( \pm 0.1 \mathrm{I})$ & $1.8( \pm 0.11) \times 10^{8}$ & $8.2( \pm 0.22) \times 10^{8}$ & $4.1( \pm 0.15) \times 10^{8}$ \\
\hline & 3 & $0.67 \mathrm{I}( \pm 0.1 \mathrm{I})$ & $0.667( \pm 0.12)$ & $0.657( \pm 0.12)$ & $8.6( \pm 0.23) \times 10^{9}$ & $3.6( \pm 0.36) \times 10^{9}$ & $3.5( \pm 0.22) \times 10^{10}$ \\
\hline & 7 & $0.832( \pm 0.14)$ & $0.844( \pm 0.04)$ & $0.840( \pm 0.04)$ & $6.2( \pm 0.49) \times 10^{9}$ & $4.2( \pm 0.15) \times 10^{10}$ & $1.2( \pm 0.32) \times 10^{10}$ \\
\hline \multirow[t]{3}{*}{ Urine } & I & $0.243( \pm 0.09)$ & $0.265( \pm 0.19)$ & $0.255( \pm 0.19)$ & $1.0( \pm 0.59) \times 10^{6}$ & $3.6( \pm 0.02) \times 10^{6}$ & $4.8( \pm 0.14) \times 10^{6}$ \\
\hline & 3 & $0.356( \pm 0.14)$ & $0.347( \pm 0.04)$ & $0.356( \pm 0.04)$ & $6.3( \pm 0.47) \times 10^{7}$ & $8.3( \pm 0.06) \times 10^{8}$ & $2.8( \pm 0.21) \times 10^{8}$ \\
\hline & 7 & $0.447( \pm 0.17)$ & $0.456( \pm 0.13)$ & $0.464( \pm 0.13)$ & $7.1( \pm 0.25) \times 10^{8}$ & $4.2( \pm 0.36) \times 10^{9}$ & $7.2( \pm 0.47) \times 10^{9}$ \\
\hline \multirow[t]{3}{*}{ Plasma } & I & $0.108( \pm 0.14)$ & $0.111( \pm 0.04)$ & $0.122( \pm 0.04)$ & $4.9( \pm 0.88) \times 10^{4}$ & $6.3( \pm 0.08) \times 10^{4}$ & $3.6( \pm 0.36) \times 10^{4}$ \\
\hline & 3 & $0.223( \pm 0.08)$ & $0.211( \pm 0.18)$ & $0.210( \pm 0.18)$ & $3.2( \pm 0.92) \times 10^{5}$ & $1.5( \pm 0.63) \times 10^{4}$ & $2.8( \pm 0.15) \times 10^{5}$ \\
\hline & 7 & $0.299( \pm 0.20)$ & $0.245( \pm 0.05)$ & $0.285( \pm 0.05)$ & $1.2( \pm 0.13) \times 10^{5}$ & $3.6( \pm 0.25) \times 10^{5}$ & $5.6( \pm 0.03) \times 10^{6}$ \\
\hline
\end{tabular}

Notes: Biofilm biomass quantification and viable count of the biofilm cells of $\mathrm{S}$. aureus grown in TSB-Glu, urine, and plasma on a catheter exposed to fluorine (0.5 $\mathrm{mg} / \mathrm{mL}$ ), and magnesium ions $(0.5 \mathrm{mg} / \mathrm{mL})$. Catheters incubated for 7 days at $37^{\circ} \mathrm{C}$. Values in parentheses represent the standard deviation of three independent experiments conducted in triplicates. Abbreviations: Glu, glucose; TSB, tryptic soy broth. 


\section{Publish your work in this journal}

The International Journal of Nanomedicine is an international, peerreviewed journal focusing on the application of nanotechnology in diagnostics, therapeutics, and drug delivery systems throughout the biomedical field. This journal is indexed on PubMed Central, MedLine, CAS, SciSearch $\AA$, Current Contents ${ }^{\circledR} /$ Clinical Medicine,

Journal Citation Reports/Science Edition, EMBase, Scopus and the Elsevier Bibliographic databases. The manuscript management system is completely online and includes a very quick and fair peer-review system, which is all easy to use. Visit http://www.dovepress.com/ testimonials.php to read real quotes from published authors.

Submit your manuscript here: http://www.dovepress.com/international-journal-of-nanomedicine-journal 